\title{
Oxygen Therapy in Chronic Obstructive Pulmonary Disease
}

\author{
Victor Kim¹, Joshua O. Benditt², Robert A. Wise ${ }^{3}$, and Amir Sharafkhaneh4 \\ ${ }^{1}$ Division of Pulmonary and Critical Care Medicine, Temple University School of Medicine, Philadelphia, Pennsylvania; ${ }^{2}$ University of Washington \\ Medical Center, Pulmonary and Critical Care Medicine, Seattle, Washington; ${ }^{3}$ Division of Pulmonary and Critical Care Medicine, The Johns Hopkins \\ University School of Medicine, Baltimore, Maryland; and ${ }^{4}$ Department of Pulmonary Medicine, Veterans Administration Medical Center, \\ Houston, Texas
}

\begin{abstract}
Since the introduction of oxygen as a therapeutic agent 70 years ago, much has been learned regarding the detrimental effects of hypoxemia and the beneficial impact of oxygen therapy. It is projected that there are close to 800,000 patients receiving long-term oxygen therapy (LTOT) in the United States, at a cost of approximately $\$ 1.8$ billion annually. The large numbers of patients receiving supplemental oxygen as treatment and the high costs incurred in providing oxygen therapy necessitate the practitioner to know the indications for LTOT as well its effects on survival, pulmonary hemodynamics, sleep, and exercise capacity. It is now recognized that the basis for LTOT prescription for all patients is founded on data that are over $\mathbf{2 5}$ years old and that only involve a very select cohort of patients. It is clear that further studies are required to assess the effects of oxygen on patients with chronic obstructive pulmonary disease with only mild hypoxemia, not only survival but also on neurocognitive function, quality of life, exercise physiology, and sleep quality. In addition, although proven to be safe when prescribed long term to individuals with lung disease, there are some concerns about worsening carbon dioxide retention and increased oxidant injury. The goals of this article are to briefly describe the indications for chronic oxygen administration, the physiologic effects of treatment, and potential toxicities, as well as its effect on morbidity and mortality.
\end{abstract}

Keywords: chronic obstructive pulmonary disease; oxygen therapy; long-term oxygen therapy; nocturnal oxygen desaturation; hypoxemia

Since the introduction of oxygen as a therapeutic agent 70 years ago, much has been learned regarding the detrimental effects of hypoxemia and the beneficial impact of oxygen therapy. It is projected that there are close to 800,000 patients receiving longterm oxygen therapy (LTOT) in the United States, at a cost of approximately $\$ 1.8$ billion annually (1). The large numbers of patients receiving supplemental oxygen as treatment and the high costs incurred in providing oxygen therapy necessitate the practitioner to know the indications for LTOT as well its effects on survival, pulmonary hemodynamics, sleep, and exercise capacity. It is now recognized that the basis for LTOT prescription for all patients is founded on very old data ( $>25 \mathrm{yr})$ in a very select patient group. It is clear that further studies are required to assess the effects of oxygen on patients with chronic

\footnotetext{
(Received in original form August 14, 2007; accepted in final form November 3, 2007) The National Emphysema Treatment Trial (NETT) is supported by contracts with the National Heart, Lung, and Blood Institute (N01HR76101, N01HR76102, N01HR76103, N01HR76104, N01HR76105, N01HR76106, N01HR76107, N01HR76108, N01HR76109, N01HR76110, N01HR76111, N01HR76112, N01HR76113, N01HR76114, N01HR76115, N01HR76116, N01HR76118, and N01HR76119), the Centers for Medicare and Medicaid Services (CMS), and the Agency for Healthcare Research and Quality (AHRQ).

Correspondence and requests for reprints should be addressed to Victor Kim, M.D., Temple University School of Medicine, 785 Parkinson Pavilion, 3401 North Broad Street, Philadelphia, PA 19140. E-mail: victor.kim@tuhs.temple.edu

Proc Am Thorac Soc Vol 5. pp 513-518, 2008

DOI: 10.1513/pats.200708-124ET

Internet address: www.atsjournals.org
}

obstructive pulmonary disease (COPD) with only mild hypoxemia on not only survival but also on neurocognitive function, quality of life, exercise physiology, and sleep quality. In addition, although proven to be safe when prescribed long term to individuals with lung disease, there are some concerns about worsening carbon dioxide retention and increased oxidant injury. The goals of this article are to briefly describe the indications for chronic oxygen administration, the physiologic effects of treatment, and potential toxicities, as well as its effect on long-term morbidity and mortality.

\section{EFFECTS OF HYPOXEMIA}

Hypoxemia has several physiologic consequences. There is no significant increase in ventilation with decreases in $\mathrm{Pa}_{\mathrm{O}_{2}}$ that results in levels remaining above $60 \mathrm{~mm} \mathrm{Hg}$, but as $\mathrm{Pa}_{\mathrm{O}_{2}}$ falls below $55 \mathrm{~mm} \mathrm{Hg}$, there is a marked rise in minute ventilation $\left(\dot{\mathrm{V}}_{\mathrm{E}}\right)$, with a subsequent fall in $\mathrm{Pa}_{\mathrm{CO}_{2}}$. Hypoxemia causes peripheral vascular beds to dilate, which induces a compensatory tachycardia and a subsequent increase in cardiac output to improve oxygen delivery. Regional pulmonary vasoconstriction occurs in response to alveolar hypoxia in an effort to match ventilation and perfusion. Erythropoietin secretion increases causing erythrocytosis, thereby increasing oxygen carrying capacity. These compensatory mechanisms can cause detrimental long-term effects, such as polycythemia, pulmonary hypertension, and right ventricular failure. On a cellular level, mitochondrial function declines, anaerobic glycolysis occurs, and lactate/pyruvate ratio increases. Patients may have impaired judgment at low levels of hypoxemia, with progressive loss of cognitive and motor functions, and eventually loss of consciousness as severe hypoxemia ensues. Other nonspecific symptoms of hypoxemia include headache, breathlessness, palpitations, angina, restlessness, and tremor.

\section{SHORT-TERM EFFECTS OF OXYGEN ADMINISTRATION}

In addition to relieving arterial hypoxemia and alleviation of the consequences listed above, supplemental oxygen has several therapeutic benefits. Oxygen improves breathlessness in both normal subjects and in those with COPD during exercise (2-4). Exercise tolerance is improved in those who develop significant hypoxemia as well as in those with only mild to moderate hypoxemia (5). Although this phenomenon has been observed by many investigators, the responsible mechanisms remain a matter of debate. In COPD, the perceived decrease in breathlessness and improvement in exercise capacity may be due to decreased $\dot{V}_{\mathrm{E}}$ (4), a decrease in dynamic hyperinflation (6), alleviation of hypoxic pulmonary vasoconstriction and improved hemodynamics (e.g., decrease in pulmonary vascular resistance and increase in cardiac output) (7), or increased oxygen delivery (8). O'Donnell and colleagues (6) performed cardiopulmonary exercise tests in 11 hypoxic and hypercapnic patients with severe COPD $\left(\mathrm{Pa}_{\mathrm{O}_{2}}, 52 \pm 2 \mathrm{~mm} \mathrm{Hg}\right.$, and $\mathrm{Pa}_{\mathrm{CO}_{2}}, 48 \pm 2 \mathrm{~mm} \mathrm{Hg}$, respectively) while breathing room air or $60 \% \mathrm{FI}_{\mathrm{O}_{2}}$ in random 
order. Oxygen administration resulted in a decrease in dyspnea scores, higher inspiratory capacity, and decreased respiratory rate compared with room air. Dean and coworkers (7) randomized 12 patients with severe COPD to compressed air or $40 \%$ inhaled oxygen during exercise. In those treated with oxygen, cycle ergometry endurance time increased by $40 \%$, maximal right ventricular systolic pressures (via Doppler echocardiography) decreased, and the rate of rise of right ventricular systolic pressure was decreased. Morrison and Stovall found that hypoxemic patients with COPD who showed an improvement in exercise capacity with supplemental oxygen had significant increases in both cardiac output and oxygen content during exercise (8).

Alternative proposed mechanisms include an improvement in ventilatory muscle function (9) and altered ventilatory muscle recruitment (10). Oxygen flow may also stimulate upper airway and facial receptors of the trigeminal nerve and reflexively inhibit central ventilatory drive (11). Finally, there also appears to be a direct effect of oxygen administration on the perception of dyspnea independent of any changes in $\dot{V}_{E}$ (3). On the basis of these studies, it has been recommended by some to use supplemental oxygen for all patients with COPD while undergoing pulmonary rehabilitation. However, the current evidence does not support the routine use of oxygen in normoxemic patients with COPD during exercise (12).

Oxygen administration decreases VE and work of breathing during acute respiratory failure (ARF) in COPD. A study conducted in 20 patients with COPD, both in a chronic stable condition and during ARF, found no difference in $\dot{V}_{E}$ between patients with chronic, stable COPD and normal control subjects (13). In ARF, however, application of oxygen at $5 \mathrm{~L} /$ minute decreased $\dot{V}_{E}$ by $14 \%$, mostly by a decrease in respiratory rate without a compensatory increase in tidal volume. ARF was also associated with increased work of breathing, as evidenced by a fivefold increase in mouth occlusion pressure. This rise in mouth occlusion pressure decreased by $40 \%$ after oxygen administration. These effects of oxygen on ventilation and work of breathing may help prevent respiratory muscle fatigue during ARF, particularly in patients with chronic respiratory insufficiency who have a higher baseline ventilatory demand.

\section{EFFECT OF LTOT ON MORTALITY}

Chronic hypoxemia leading to the development of cor pulmonale portends a poor prognosis, with mortality ranging anywhere from 32 to $100 \%(14,15)$. Early noncontrolled studies showed a reduction in mortality in patients with COPD, cor pulmonale, and severe hypoxemia with the use of continuous oxygen therapy for 7 to 41 months (16). Two landmark studies performed in the late 1970s, the Nocturnal Oxygen Therapy Trial (NOTT) (17) and the British Medical Research Council (MRC) Long-Term Domiciliary Oxygen Therapy Trial (18), examined the effects of LTOT on survival and physiologic function in patients with severe chronic bronchitis and emphysema.

The British MRC trial (18) was conducted in the late 1970s and reported in March of 1981. It was performed in three centers in the United Kingdom and enrolled 87 patients, all younger than 70 years, who had chronic bronchitis or emphysema with irreversible airway obstruction $\left(\mathrm{FEV}_{1}\right.$ range, $0.58-$ $0.75 \mathrm{~L})$, severe hypoxemia $\left(\mathrm{Pa}_{\mathrm{O}_{2}}\right.$ range, 49.4-51.8 mm Hg), carbon dioxide retention $\left(\mathrm{Pa}_{\mathrm{CO}_{2}}, 56-60 \mathrm{~mm} \mathrm{Hg}\right)$, and a history of cor pulmonale (mean pulmonary artery pressure range, 32.3$35.0 \mathrm{~mm} \mathrm{Hg}$ ). Patients randomized to receive oxygen were given $2 \mathrm{~L} /$ minute of oxygen via nasal prongs for at least 15 hours a day. In 5 years of survival follow-up, 19 of the 42 oxygentreated patients died, compared with 30 of 45 control subjects who did not receive oxygen and died. Mortality appeared to be highest in the subgroup of patients who had the highest elevations in baseline $\mathrm{Pa}_{\mathrm{CO}_{2}}$ and red cell mass. Although mortality was favorably affected by long-term oxygen use, there were no statistically significant differences in the rate of decrease of $\mathrm{FEV}_{1}$ or $\mathrm{Pa}_{\mathrm{O}_{2}}$, or increase in $\mathrm{Pa}_{\mathrm{CO}_{2}}$, red cell mass, or pulmonary artery pressures. However, there appeared to be a trend that LTOT prevented a progressive decrease in $\mathrm{Pa}_{\mathrm{O}_{2}}$ and in the rate of increase in pulmonary vascular resistance without provoking a further increase in $\mathrm{Pa}_{\mathrm{CO}_{2}}$.

The NOTT (17), sponsored by the National Heart, Lung, and Blood Institute, reported the effects of continuous versus nocturnal oxygen therapy in hypoxemic patients with COPD. This multicenter study enrolled 203 hypoxemic patients with COPD who were randomly allocated to receive either continuous oxygen therapy or 12 hours of nocturnal oxygen therapy. All subjects were followed for at least 12 months to determine the effects of oxygen therapy on survival, pulmonary vascular pressures, neuropsychological function, and quality of life. Mortality in the 203 patients was followed for an average of 19.3 months. Eighty nocturnal oxygen and 87 continuous oxygen therapy subjects were followed for 12 months, whereas 29 nocturnal oxygen and 37 continuous oxygen therapy patients were followed for 24 months. Overall mortality of the subjects assigned to continuous oxygen therapy and nocturnal oxygen therapy over 3 years of observation is shown in Figure 1. A total of 64 subjects died in the trial, 41 in the nocturnal oxygen therapy group and 23 in the continuous oxygen therapy group. At all six centers, mortality for the nocturnal oxygen therapy group exceeded that for the continuous oxygen therapy group.

When the effect of continuous versus nocturnal therapy was assessed for its impact on physiologic variables, no significant changes were found in arterial blood gas values, lung volumes, $\mathrm{FEV}_{1}$, maximum work attained, mean pulmonary artery pressures, or cardiac index. However, hematocrit values were more reduced in patients on continuous oxygen therapy than those randomized to nocturnal treatment ( $\sim 7 \%$ difference), as was pulmonary vascular resistance $(17.6 \%$ greater decrease in pulmonary vascular resistance found in the group receiving continuous vs. nocturnal therapy).

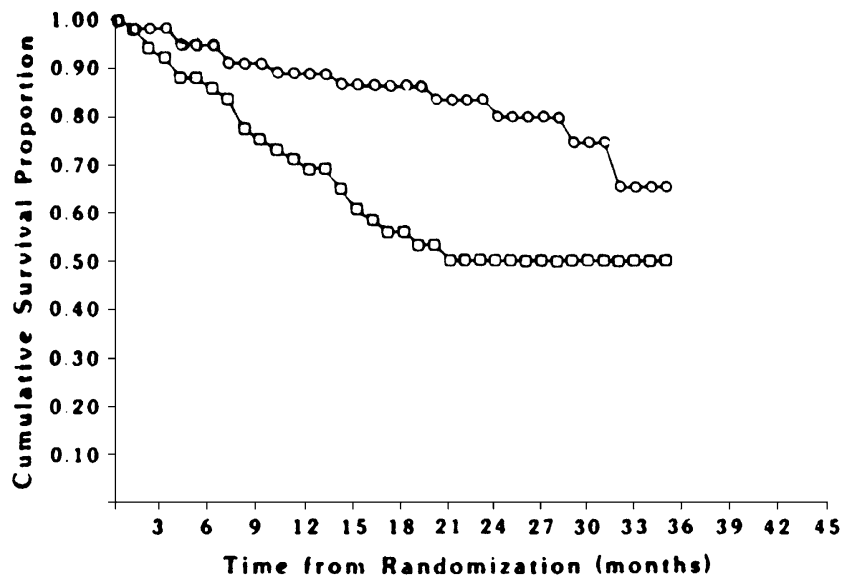

Figure 1. Overall mortality in the patients enrolled in the National Oxygen Treatment Trial. Circles (upper curve) represent continuous oxygen therapy group. Squares (lower curve) represent nocturnal oxygen therapy group. Twelve-month mortality in the nocturnal oxygen group was $20.6 \%$, versus $11.9 \%$ in the continuous oxygen therapy group. Twenty-four-month mortality in the nocturnal oxygen group was $40.8 \%$ versus $22.4 \%$ in the continuous oxygen treatment group. Reprinted by permission from Reference 17 . 
TABLE 1. COMPARSION OF BRITISH MEDICAL RESEARCH COUNCIL AND NOCTURNAL OXYGEN THERAPY TRIAL LONG-TERM OXYGEN TREATMENT TRIALS

\begin{tabular}{|c|c|c|}
\hline & MRC & NOTT \\
\hline Number & 87 & 203 \\
\hline Study design & Prospective, controlled & Prospective, controlled \\
\hline Protocol & No $\mathrm{O}_{2}$ vs. nocturnal use & Nocturnal vs. continuous use \\
\hline $\mathrm{FEV}_{1}$ & $0.58-0.76 \mathrm{~L}$ & $29 \%$ predicted \\
\hline Female, \% & 24 & $20-23$ \\
\hline $\mathrm{Pa}_{\mathrm{O}_{2}}, \mathrm{~mm} \mathrm{Hg}$ & $49-51$ & 51 \\
\hline $\mathrm{Pa}_{\mathrm{CO}_{2}}, \mathrm{~mm} \mathrm{Hg}$ & $55-60$ & 43 \\
\hline MPAP, $\mathrm{mm} \mathrm{Hg}$ & $32-35$ & 30 \\
\hline Hours of $\mathrm{O}_{2}$ use/d & 0 vs. 15 & $12 \pm 2.5$ vs. $17.7 \pm 4.8$ \\
\hline Smoking status & $25-52 \%$ & - \\
\hline
\end{tabular}

Definition of abbreviations: MPAP = mean pulmonary artery pressure; MRC = Medical Research Council; NOTT = Nocturnal Oxygen Therapy Trial.

Modified by permission from Reference 55 .

It should be recognized that, although both of the above studies showed improved survival, patients were not comparable between studies (Table 1). Patients in the MRC study tended to be more ill and with more evidence of resting hypercapnia and cor pulmonale. Furthermore, patients in the MRC study had a significant number of participants who continued to smoke even after enrollment into the trial $(27 \%$ in the control group and $44 \%$ in the placebo group), whereas no comment was made on the incidence of continued smoking in NOTT patients. Finally, the MRC study found no statistically significant impact of nocturnal oxygen therapy versus no oxygen treatment on physiologic variables, whereas the NOTT study found a statistically significantly greater decrease in pulmonary vascular resistance and absolute hematocrit associated with continuous oxygen therapy. The causal relationship between a reduction in hematocrit and pulmonary vascular resistance on influencing survival, whether using continuous or nocturnal oxygen therapy, was not established, however.

Despite their differences, these two prospective and controlled trials appear to establish that nocturnal oxygen therapy is better than no oxygen therapy at all, and continuous oxygen therapy is better than nocturnal oxygen therapy in severely hypoxemic patients with elevated hematocrit, pulmonary artery pressure, and respiratory acidosis. In an attempt to extend the above findings to patients who suffer from less severe disease and only moderate hypoxemia, Gorecka and colleagues (19) evaluated 135 patients $\left(\mathrm{Pa}_{\mathrm{O}_{2}}, 56-65 \mathrm{~mm} \mathrm{Hg}\right.$ at rest) with advanced airflow obstruction $\left(\mathrm{FEV}_{1}, 0.83 \mathrm{~L}\right)$ who were randomly allocated to receive no oxygen therapy or LTOT. Patients assigned to either group were followed every 3 months for at least 3 years. The cumulative survival rates for the group at large were $88 \%$ at 1 year, $77 \%$ at 2 years, and $66 \%$ at 3 years. The authors found no significant difference in survival rates between the two patient groups treated with LTOT versus control therapy. Patients who were younger, had better spirometric values, and had higher body mass index showed better survival. This was similar to the findings of other studies, in which no survival benefit was found in patients with COPD given supplemental oxygen when severe hypoxemia or cor pulmonale was not present.

Similarly, no study has shown a survival benefit when oxygen is prescribed for exercise-induced oxygen desaturation. Most recently, the National Emphysema Treatment Trial (NETT) research group performed a retrospective analysis on the normoxemic participants in the medical arm of NETT (unpublished data). They found that the normoxemic patients who reported continuous oxygen use had greater dyspnea, lower quality of life, worse lung function, worse exercise capacity, and more frequent exercise desaturation compared with the normoxemic patients who did not use oxygen therapy. In those who experienced desaturation during exercise, no difference in survival was found based on reported oxygen use. It must be noted, however, that oxygen use was not given in a prospective, randomized fashion, and the available data may help identify a sicker group of patients with a greater risk of death.

\section{OXYGEN THERAPY AND PULMONARY HEMODYNAMICS IN COPD}

Substantial evidence suggests that the presence of secondary pulmonary hypertension in COPD increases the risk for hospitalization (20) and is associated with worsened survival $(21,22)$. Because of the known association of resting hypoxemia with the development of secondary pulmonary hypertension, investigators have focused on supplemental oxygen as treatment for hypoxemic COPD patients with pulmonary hypertension. Data from the NOTT group found that oxygen therapy in hypoxemic patients with COPD is associated with favorable but minimal changes in the magnitude of pulmonary hypertension at rest and during exercise (23). Furthermore, they tend to suggest that favorable changes in pulmonary hemodynamics secondary to oxygen supplementation are enhanced in the group of patients that receives oxygen continuously, compared with those who receive it on an intermittent daily basis (23). It is difficult to attribute the improvements in survival of patients with COPD receiving continuous versus nocturnal oxygen therapy solely to changes in pulmonary hemodynamics on the basis of the available data. In addition, the response to acute administration of oxygen on pulmonary hemodynamics does not appear to predict the long-term effects of oxygen therapy on survival (24). Further studies are required to determine the causal relationship of oxygen supplementation on pulmonary hemodynamics and survival, and to predict which subgroups of patients with pulmonary hypertension and hypoxemic COPD are more likely to benefit from long-term administration.

\section{OXYGENATION AND SLEEP IN COPD}

Sleep disturbance is common in patients with COPD. Increased sleep latency, decreased total sleep time, decreased slow-wave sleep, and decreased REM sleep have been noted in many polysomnographic studies of patients with COPD (25-29). Approximately 30 to $70 \%$ of patients with COPD complain of insomnia, early morning awakenings, morning tiredness, or daytime sleepiness (29-31). Common reasons include medication side effects, airflow obstruction, and hypercapnia, but perhaps the most important is nocturnal oxygen desaturation (NOD). Approximately 25 years ago, Koo and colleagues (32) studied 15 normoxemic patients with severe COPD $\left(\mathrm{FEV}_{1}, 0.96\right.$ $\mathrm{L})$ and found a mean decrease in $\mathrm{Pa}_{\mathrm{O}_{2}}$ of $13.5 \mathrm{~mm} \mathrm{Hg}$ and a mean increase of $\mathrm{Pa}_{\mathrm{CO}_{2}}$ of $8.3 \mathrm{~mm} \mathrm{Hg}$ during REM sleep. Up to $25 \%$ of patients with COPD exhibit REM-related hypoventilation and NOD, despite having a daytime $\mathrm{Pa}_{\mathrm{O}_{2}}$ above $60 \mathrm{~mm}$ $\mathrm{Hg}$ (33). Determining who will develop NOD is difficult without nocturnal oximetry or polysomnography; assessments of daytime gas exchange or pulmonary function are unable to differentiate those patients who experience desaturation at night and those who do not $(33,34)$. It has been suggested that oxygen therapy improves sleep continuity and quality in those who experience desaturation (27), although this phenomenon has not been demonstrated in all studies (see Table 2) (27).

NOD may lead to the development of pulmonary hypertension and cor pulmonale in patients with COPD. Levi-Valensi and coworkers (34) investigated the relationship between sleep 
TABLE 2. EFFECTS OF OXYGEN ON SLEEP QUALITY IN CHRONIC OBSTRUCTIVE PULMONARY DISEASE WITH NOCTURNAL OXYGEN DESATURATION

\begin{tabular}{lcc}
\hline Variable & $\begin{array}{c}\text { Calverley }(27) \\
(n=6)\end{array}$ & $\begin{array}{c}\text { Fleetham (28) } \\
(n=15)\end{array}$ \\
\hline Total sleep time & Increased & No change \\
Stages 3/4 sleep & Increased & No change \\
REM sleep & Increased & No change \\
Arousals/uninterrupted sleep & Decreased & No change \\
\hline
\end{tabular}

variables and daytime pulmonary hemodynamics in 40 patients with COPD with daytime $\mathrm{Pa}_{\mathrm{O}_{2}}$ of 60 to $70 \mathrm{~mm} \mathrm{Hg}$. Mean pulmonary artery pressure was higher in those who demonstrated significant oxygen desaturation compared with those who did not $(19.1 \pm 4.7$ vs. $16.9 \pm 1.9 \mathrm{~mm} \mathrm{Hg}$, respectively). Oxygen therapy during sleep may prevent nocturnal hypoxemia and possibly the development of pulmonary hypertension. However, two recent clinical studies examining normoxemic patients with COPD with evidence of nocturnal desaturation found neither an improvement in survival with nocturnal oxygen despite a reduction in pulmonary artery pressures nor a delay in the time to prescription of continuous oxygen therapy $(35,36)$. Therefore, similar to exercise-induced hypoxemia, it is unclear whether LTOT in this circumstance has long-term benefits. Given the lack of survival advantage, screening for nocturnal desaturation in normoxemic patients with COPD should probably be reserved for those with hypercapnia, erythrocytosis, or evidence of pulmonary hypertension.

\section{OXYGEN AND AIR TRAVEL}

Ascent to high altitude via air travel exposes patients to hypobaric conditions, which increases risk of hypoxemia. Pressurizing the aircraft cabin limits the fall in atmospheric pressure to an altitude of $8,000 \mathrm{ft}$, allowing ascent to much higher altitudes. Oxygen supplementation is indicated if the predicted $\mathrm{Pa}_{\mathrm{O}_{2}}$ at $8,000 \mathrm{ft}$ is less than $50 \mathrm{~mm} \mathrm{Hg}$. Those with an $\mathrm{Sp}_{\mathrm{O}_{2}}$ greater than $95 \%$ or a $\mathrm{Pa}_{\mathrm{O}_{2}}$ greater than $72 \mathrm{~mm} \mathrm{Hg}$ while breathing ambient air at sea level will most likely not require oxygen supplementation. For those who do not meet these criteria, an equation has been advocated to predict $\mathrm{Pa}_{\mathrm{O}_{2}}$ at an 8,000 -ft altitude in normocapnic patients with COPD (37):

$$
\begin{aligned}
\mathrm{Pa}_{2} \text { at } 8,000 \mathrm{ft}= & {\left[0.238 \times\left(\mathrm{Pa}_{\mathrm{O}_{2}} \text { sea level }\right)\right] } \\
& +\left[20.098 \times\left(\mathrm{FEV}_{1} / \mathrm{FVC}\right)\right]+22.258
\end{aligned}
$$

Determining the liter flow needed to restore normoxemia during flight is slightly more difficult. In one series, the use of $2 \mathrm{~L} /$ minute of supplemental oxygen was sufficient for those who did not require oxygen at sea level (38). Predicting the liter flow for those who already require oxygen at sea level can be done with a hypoxic gas inhalation test (39). Using a 35\% Venturi mask with nitrogen as the supply gas instead of oxygen, the entrained ambient air will result in a fraction of inspired oxygen of $16 \%$, thereby mimicking the hypoxic conditions at approximately 6,700 ft. The $\mathrm{Pa}_{\mathrm{O}_{2}}$ can be measured while the patient is breathing in supplemental oxygen through a nasal cannula.

\section{INDICATIONS FOR LTOT}

The indications for LTOT are summarized in Table 3. The requirements for medical necessity for Medicare coverage have been based primarily on the entry criteria for the NOTT (17), but have been refined on the basis of five consensus conferences on LTOT $(40,41)$. These guidelines apply not only to hypoxemic patients with COPD but also to those with hypoxemia secondary to other pulmonary and cardiac diseases (38).

LTOT is indicated for those who are hypoxemic at rest $\left(\mathrm{Pa}_{\mathrm{O}_{2}}<55 \mathrm{~mm} \mathrm{Hg}\right.$ or $\left.\mathrm{Sa}_{\mathrm{O}_{2}}<88 \%\right)$ or who have borderline hypoxemia $\left(\mathrm{Pa}_{\mathrm{O}_{2}}, 56-59 \mathrm{~mm} \mathrm{Hg}\right.$, or $\left.\mathrm{Sa}_{\mathrm{O}_{2}}<89 \%\right)$ with evidence of cor pulmonale or polycythemia. In addition, many of those with resting hypoxemia will have increased oxygen requirements during exertion and sleep, so it is prudent for the clinician caring for these patients to assess their oxygen needs during these situations. In the United States, Medicare also allows oxygen to be prescribed during sleep if $\mathrm{Pa}_{\mathrm{O}_{2}}$ is less than $55 \mathrm{~mm}$ $\mathrm{Hg}, \mathrm{Sa}_{\mathrm{O}_{2}}$ is less than $88 \%$, or if there is a fall in $\mathrm{Pa}_{\mathrm{O}_{2}}$ of more than $10 \mathrm{~mm} \mathrm{Hg}$ or a fall in $\mathrm{Sa}_{\mathrm{O}_{2}}$ of more than $5 \%$ with signs or symptoms of hypoxemia. The latter indication is defined by the Center for Medicare and Medicaid Services as "impaired cognitive process, restlessness, or insomnia." Oxygen may also be prescribed during exercise if the $\mathrm{Pa}_{\mathrm{O}_{2}}$ falls to $55 \mathrm{~mm} \mathrm{Hg}$ or the $\mathrm{Sa}_{\mathrm{O}_{2}}$ falls to $88 \%$.

\section{ACCENTUATION OF HYPERCAPNIA}

Of concern are worsening carbon dioxide retention and respiratory acidosis when oxygen is administered to patients with chronic hypercapnia. The most commonly believed mechanism for this phenomenon is the blunting of hypoxic ventilatory drive and hypoventilation. Aubier and colleagues (42) administered $100 \%$ oxygen noninvasively to patients with COPD and ARF, which resulted in an acute $18 \%$ decrease in $\dot{V}_{\text {E. After }} 15$ minutes of breathing $100 \%$ oxygen, however, $\dot{V}_{E}$ returned to $93 \%$ of baseline values while breathing room air. Despite the near normalization of ventilation, the $\mathrm{Pa}_{\mathrm{CO}_{2}}$ increased about $23 \mathrm{~mm}$ $\mathrm{Hg}$, and the average $\mathrm{Pa}_{\mathrm{O}_{2}}$ reached $225 \mathrm{~mm} \mathrm{Hg}$. Approximately $5 \mathrm{~mm} \mathrm{Hg}(22 \%)$ was attributed to the decrease in $\dot{\mathrm{V}}_{\mathrm{E}} ; 7 \mathrm{~mm} \mathrm{Hg}$ $(30 \%)$ was attributed to a reduction of hemoglobin's affinity to bind and carry $\mathrm{CO}_{2}$, also known as the Haldane effect. Oxyhemoglobin shifts the $\mathrm{CO}_{2}$ hemoglobin dissociation curve to the right, thereby increasing the amount of $\mathrm{CO}_{2}$ dissolved in blood, which determines $\mathrm{Pa}_{\mathrm{CO}_{2}}$. The largest component of acute hypercapnia (11 $\mathrm{mm} \mathrm{Hg}, 48 \%$ ) was attributed to increased dead-space ventilation. Therefore, it seems that acute administration of supranormal levels of oxygen to patients with COPD and with

TABLE 3. INDICATIONS FOR LONG-TERM OXYGEN THERAPY

\begin{tabular}{lc}
\hline $\begin{array}{l}\text { Absolute } \\
\text { In presence of cor pulmonale }\end{array}$ & $\mathrm{Pa}_{\mathrm{O}_{2}} \leqslant 55 \mathrm{~mm} \mathrm{Hg}$ or $\mathrm{Sa}_{\mathrm{O}_{2}} \leqslant 88 \%$ \\
& $\mathrm{~Pa}_{\mathrm{O}_{2}} 55-59 \mathrm{~mm} \mathrm{Hg}$ or Sa $\mathrm{O}_{2} \leqslant 89 \%$, ECG evidence of right atrial enlargement, \\
hematocrit $>55 \%$, congestive heart failure & $\mathrm{Pa}_{\mathrm{O}_{2}} \geqslant 60 \mathrm{~mm} \mathrm{Hg}$ or Sa $\mathrm{O}_{2} \geqslant 90 \%$; with lung disease and other clinical \\
Only in specific situations & needs such as sleep with nocturnal desaturation not corrected by CPAP \\
& $\mathrm{O}_{2}$ should be prescribed if $\mathrm{Pa}_{\mathrm{O}_{2}}$ falls below 55 mm Hg during exercise or \\
$\begin{array}{l}\text { If the patient is normoxemic at rest but } \\
\text { desaturates during exercise or sleep }\end{array}$ & sleep; also consider nasal CPAP or bilevel positive airway pressure
\end{tabular}

Definition of abbreviations: CPAP = continuous positive airway pressure.

Adapted by permission from Criner GJ. Effects of long-term oxygen therapy on mortality and morbidity. Respir Care 2000:45:105-118. 
ARF can lead to hypercapnia, and the primary mechanism is the release of hypoxic vasoconstriction in underventilated lung causing ventilation-perfusion imbalance, not hypoventilation. However, with controlled administration of oxygen, breathlessness can be alleviated and hypoxemia treated without significant increases in arterial carbon dioxide tension.

\section{CONTROVERSIES AND CONCERNS}

Who will benefit from LTOT needs to be refined, with more rigorous collection of outcome data in a variety of patient populations. The data showing survival benefit of LTOT in hypoxemic patients with COPD are more than 25 years, and no study since then has shed any further light on its therapeutic potential. As an example, three studies have found no survival benefit in COPD with only mild hypoxemia in the absence of cor pulmonale or severe desaturation $(16,19,43)$. The average use of oxygen in these studies was, however, 13.5 hours/day or less, which may have been an inadequate duration to show a survival advantage. Nevertheless, other benefits of oxygen therapy in this group may include improvement in symptoms of depression and anxiety, neuropsychological function, exercise capacity, and quality of life (44-46). Further studies are necessary to delineate which patients with mild hypoxemia would have a survival benefit, and what other therapeutic benefits may be derived from oxygen therapy.

LTOT has potential consequences as well. In addition to accentuation of hypercapnia, chronic oxygen therapy may also accelerate oxidant injury. Hyperoxia can produce cellular injury through production of reactive oxygen species, which can result in tissue inflammation and cell death $(47,48)$. Recent studies have shown that supplemental oxygen increases exhaled biomarkers of oxidative stress and airway inflammation (49-52). In contrast, in one study of nine normoxemic, cachectic patients with COPD, short-term oxygen supplementation had no effect on plasma inflammatory biomarkers while at rest and actually decreased evidence of exercise-induced oxidative stress (53). Interestingly, the NETT research group found that oxygen use was an independent risk factor for death compared with those not using oxygen therapy (hazard ratio, 1.36; $95 \%$ confidence interval, 1.02-2.10) in those randomized to the medical arm of the NETT (54). Whether oxygen use contributed to earlier mortality or simply was an epimarker of a sicker patient group is difficult to discern on the basis of their data. In light of these findings, the growing body of literature linking oxidant injury to COPD pathogenesis makes the potential toxicity of LTOT difficult to ignore and underscores the importance of identifying the optimal candidate.

\section{CONCLUSIONS}

Oxygen therapy offers significant short- and long-term benefits in those with COPD. Immediate benefits include alleviation of hypoxemia and its sequelae, improvement in exercise capacity, reduction of dyspnea, and possibly sleep consolidation. Longterm use has been shown to improve survival in severely hypoxemic patients with COPD and cause a slight reduction in pulmonary artery pressure. On the basis of the above studies, patients with a resting $\mathrm{Pa}_{\mathrm{O}_{2}}$ of less than $55 \mathrm{~mm} \mathrm{Hg}\left(\mathrm{Sa}_{\mathrm{O}_{2}}<\right.$ $88 \%$ ), those with a $\mathrm{Pa}_{\mathrm{O}_{2}}$ of $56-59 \mathrm{~mm} \mathrm{Hg}$ with signs of tissue hypoxemia (e.g., cor pulmonale, polycythemia, impaired cognition), and those who experience desaturation during sleep or exercise should be considered for LTOT. The benefits of oxygen therapy in those with mild to moderate hypoxemia, although they may not include a reduction in mortality, may include improvements in mood, neurocognitive function, and quality of life. Further randomized controlled studies are needed to confirm or refute prior data in this patient group.

Conflict of Interest Statement: None of the authors has a financial relationship with a commercial entity that has an interest in the subject of this manuscript.

\section{References}

1. O'Donohue WJ Jr, Plummer AL. Magnitude of usage and cost of home oxygen therapy in the United States. Chest 1995;107:301-302.

2. Chronos N, Adams L, Guz A. Effect of hyperoxia and hypoxia on exercise-induced breathlessness in normal subjects. Clin Sci (Lond) 1988;74:531-537.

3. Lane R, Cockcroft A, Adams L, Guz A. Arterial oxygen saturation and breathlessness in patients with chronic obstructive airways disease. Clin Sci (Lond) 1987;72:693-698.

4. Swinburn CR, Mould H, Stone TN, Corris PA, Gibson GJ. Symptomatic benefit of supplemental oxygen in hypoxemic patients with chronic lung disease. Am Rev Respir Dis 1991;143:913-915.

5. Somfay A, Porszasz J, Lee SM, Casaburi R. Dose-response effect of oxygen on hyperinflation and exercise endurance in nonhypoxaemic COPD patients. Eur Respir J 2001;18:77-84.

6. O'Donnell DE, D'Arsigny C, Webb KA. Effects of hyperoxia on ventilatory limitation during exercise in advanced chronic obstructive pulmonary disease. Am J Respir Crit Care Med 2001;163:892-898.

7. Dean NC, Brown JK, Himelman RB, Doherty JJ, Gold WM, Stulbarg MS. Oxygen may improve dyspnea and endurance in patients with chronic obstructive pulmonary disease and only mild hypoxemia. Am Rev Respir Dis 1992;146:941-945.

8. Morrison DA, Stovall JR. Increased exercise capacity in hypoxemic patients after long-term oxygen therapy. Chest 1992;102:542-550.

9. Bye PT, Esau SA, Levy RD, Shiner RJ, Macklem PT, Martin JG, Pardy RL. Ventilatory muscle function during exercise in air and oxygen in patients with chronic air-flow limitation. Am Rev Respir Dis 1985; 132:236-240.

10. Criner GJ, Celli BR. Ventilatory muscle recruitment in exercise with $\mathrm{O} 2$ in obstructed patients with mild hypoxemia. J Appl Physiol 1987;63: 195-200.

11. Manning HL, Schwartzstein RM. Pathophysiology of dyspnea. N Engl J Med 1995;333:1547-1553.

12. Nonoyama ML, Brooks D, Lacasse Y, Guyatt GH, Goldstein RS. Oxygen therapy during exercise training in chronic obstructive pulmonary disease. Cochrane Database Syst Rev 2007;2:CD005372.

13. Aubier M, Murciano D, Fournier M, Milic-Emili J, Pariente R, Derenne JP. Central respiratory drive in acute respiratory failure of patients with chronic obstructive pulmonary disease. Am Rev Respir Dis 1980; 122:191-199.

14. Boushy SF, Thompson HK Jr, North LB, Beale AR, Snow TR. Prognosis in chronic obstructive pulmonary disease. Am Rev Respir Dis 1973;108:1373-1383.

15. Jones NL, Burrows B, Fletcher CM. Serial studies of 100 patients with chronic airway obstruction in London and Chicago. Thorax 1967;22: 327-335.

16. Neff TA, Petty TL. Long-term continuous oxygen therapy in chronic airway obstruction: mortality in relationship to cor pulmonale, hypoxia, and hypercapnia. Ann Intern Med 1970;72:621-626.

17. Nocturnal Oxygen Therapy Trial Group. Continuous or nocturnal oxygen therapy in hypoxemic chronic obstructive lung disease: a clinical trial. Ann Intern Med 1980;93:391-398.

18. Medical Research Council Working Party. Long term domiciliary oxygen therapy in chronic hypoxic cor pulmonale complicating chronic bronchitis and emphysema: report of the Medical Research Council Working Party. Lancet 1981;1:681-686.

19. Gorecka D, Gorzelak K, Sliwinski P, Tobiasz M, Zielinski J. Effect of long-term oxygen therapy on survival in patients with chronic obstructive pulmonary disease with moderate hypoxaemia. Thorax 1997; 52:674-679.

20. Kessler R, Faller M, Fourgaut G, Mennecier B, Weitzenblum E. Predictive factors of hospitalization for acute exacerbation in a series of 64 patients with chronic obstructive pulmonary disease. Am J Respir Crit Care Med 1999;159:158-164.

21. Weitzenblum E, Loiseau A, Hirth C, Mirhom R, Rasaholinjanahary J. Course of pulmonary hemodynamics in patients with chronic obstructive pulmonary disease. Chest 1979;75:656-662.

22. Oswald-Mammosser M, Weitzenblum E, Quoix E, Moser G, Chaouat A, Charpentier C, Kessler R. Prognostic factors in COPD patients 
receiving long-term oxygen therapy: importance of pulmonary artery pressure. Chest 1995;107:1193-1198.

23. Timms RM, Khaja FU, Williams GW. Hemodynamic response to oxygen therapy in chronic obstructive pulmonary disease. Ann Intern Med 1985;102:29-36.

24. Sliwinski P, Hawrylkiewicz I, Gorecka D, Zielinski J. Acute effect of oxygen on pulmonary arterial pressure does not predict survival on long-term oxygen therapy in patients with chronic obstructive pulmonary disease. Am Rev Respir Dis 1992;146:665-669.

25. Krachman SL, Chatila W, Martin UJ, Nugent T, Crocetti J, Gaughan J, Criner GJ; National Emphysema Treatment Trial Research Group. Effects of lung volume reduction surgery on sleep quality and nocturnal gas exchange in patients with severe emphysema. Chest 2005; 128:3221-3228.

26. Wynne JW, Block AJ, Hemenway J, Hunt LA, Flick MR. Disordered breathing and oxygen desaturation during sleep in patients with chronic obstructive lung disease (COLD). Am J Med 1979;66:573-579.

27. Calverley PM, Brezinova V, Douglas NJ, Catterall JR, Flenley DC. The effect of oxygenation on sleep quality in chronic bronchitis and emphysema. Am Rev Respir Dis 1982;126:206-210.

28. Fleetham J, West P, Mezon B, Conway W, Roth T, Kryger M. Sleep, arousals, and oxygen desaturation in chronic obstructive pulmonary disease: the effect of oxygen therapy. Am Rev Respir Dis 1982;126:429-433.

29. Cormick W, Olson LG, Hensley MJ, Saunders NA. Nocturnal hypoxaemia and quality of sleep in patients with chronic obstructive lung disease. Thorax 1986;41:846-854.

30. Bellia V, Catalano F, Scichilone N, Incalzi RA, Spatafora M, Vergani C, Rengo F. Sleep disorders in the elderly with and without chronic airflow obstruction: the SARA study. Sleep 2003;26:318-323.

31. Klink ME, Dodge R, Quan SF. The relation of sleep complaints to respiratory symptoms in a general population. Chest 1994;105:151154.

32. Koo KW, Sax DS, Snider GL. Arterial blood gases and $\mathrm{pH}$ during sleep in chronic obstructive pulmonary disease. Am J Med 1975;58:663670 .

33. Fletcher EC, Miller J, Divine GW, Fletcher JG, Miller T. Nocturnal oxyhemoglobin desaturation in COPD patients with arterial oxygen tensions above $60 \mathrm{~mm} \mathrm{Hg}$. Chest 1987;92:604-608.

34. Levi-Valensi P, Weitzenblum E, Rida Z, Aubry P, Braghiroli A, Donner C, Aprill M, Zielinski J, Wurtemberger G. Sleep-related oxygen desaturation and daytime pulmonary haemodynamics in COPD patients. Eur Respir J 1992;5:301-307.

35. Fletcher EC, Luckett RA, Goodnight-White S, Miller CC, Qian W, Costarangos-Galarza C. A double-blind trial of nocturnal supplemental oxygen for sleep desaturation in patients with chronic obstructive pulmonary disease and a daytime $\mathrm{PaO} 2$ above $60 \mathrm{~mm} \mathrm{Hg}$. Am Rev Respir Dis 1992;145:1070-1076.

36. Fletcher EC, Donner CF, Midgren B, Zielinski J, Levi-Valensi P, Braghiroli A, Rida Z, Miller CC. Survival in COPD patients with a daytime $\mathrm{PaO} 2$ greater than $60 \mathrm{~mm} \mathrm{Hg}$ with and without nocturnal oxyhemoglobin desaturation. Chest 1992;101:649-655.

37. Dillard TA, Moores LK, Bilello KL, Phillips YY. The preflight evaluation: a comparison of the hypoxia inhalation test with hypobaric exposure. Chest 1995;107:352-357.

38. Cramer D, Ward S, Geddes D. Assessment of oxygen supplementation during air travel. Thorax 1996;51:202-203.
39. Vohra KP, Klocke RA. Detection and correction of hypoxemia associated with air travel. Am Rev Respir Dis 1993;148:1215-1219.

40. Petty TL, Casaburi R. Recommendations of the Fifth Oxygen Consensus Conference. Writing and Organizing Committees. Respir Care 2000; 45:957-961.

41. Petty TL, O'Donohue WJ Jr. Further recommendations for prescribing, reimbursement, technology development, and research in long-term oxygen therapy: summary of the Fourth Oxygen Consensus Conference, Washington, DC, October 15-16, 1993. Am J Respir Crit Care Med 1994;150:875-877.

42. Aubier M, Murciano D, Milic-Emili J, Touaty E, Daghfous J, Pariente $\mathrm{R}$, Derenne JP. Effects of the administration of $\mathrm{O} 2$ on ventilation and blood gases in patients with chronic obstructive pulmonary disease during acute respiratory failure. Am Rev Respir Dis 1980;122:747-754.

43. Chaouat A, Weitzenblum E, Kessler R, Charpentier C, Enrhart M, Schott R, Levi-Valensi P, Zielinski J, Delaunois L, Cornudella R, et al. A randomized trial of nocturnal oxygen therapy in chronic obstructive pulmonary disease patients. Eur Respir J 1999;14:1002-1008.

44. Heaton RK, Grant I, McSweeny AJ, Adams KM, Petty TL. Psychologic effects of continuous and nocturnal oxygen therapy in hypoxemic chronic obstructive pulmonary disease. Arch Intern Med 1983;143: 1941-1947.

45. Borak J, Sliwinski P, Tobiasz M, Gorecka D, Zielinski J. Psychological status of COPD patients before and after one year of long-term oxygen therapy. Monaldi Arch Chest Dis 1996;51:7-11.

46. Eaton T, Lewis C, Young P, Kennedy Y, Garrett JE, Kolbe J. Long-term oxygen therapy improves health-related quality of life. Respir Med 2004:98:285-293.

47. Barazzone C, Horowitz S, Donati YR, Rodriguez I, Piguet PF. Oxygen toxicity in mouse lung: pathways to cell death. Am J Respir Cell Mol Biol 1998;19:573-581.

48. Mantell LL, Lee PJ. Signal transduction pathways in hyperoxia-induced lung cell death. Mol Genet Metab 2000;71:359-370.

49. Carpagnano GE, Kharitonov SA, Foschino-Barbaro MP, Resta O, Gramiccioni E, Barnes PJ. Supplementary oxygen in healthy subjects and those with COPD increases oxidative stress and airway inflammation. Thorax 2004;59:1016-1019.

50. Hitka P, Vizek M, Wilhelm J. Hypoxia and reoxygenation increase $\mathrm{H} 2 \mathrm{O} 2$ production in rats. Exp Lung Res 2003;29:585-592.

51. Loiseaux-Meunier MN, Bedu M, Gentou C, Pepin D, Coudert J, Caillaud D. Oxygen toxicity: simultaneous measure of pentane and malondialdehyde in humans exposed to hyperoxia. Biomed Pharmacother 2001;55:163-169.

52. Phillips M, Cataneo RN, Greenberg J, Grodman R, Gunawardena R, Naidu A. Effect of oxygen on breath markers of oxidative stress. Eur Respir J 2003;21:48-51.

53. van Helvoort HA, Heijdra YF, Heunks LM, Meijer PL, Ruitenbeek W, Thijs HM, Dekhuijzen PN. Supplemental oxygen prevents exerciseinduced oxidative stress in muscle-wasted patients with chronic obstructive pulmonary disease. Am J Respir Crit Care Med 2006;173: 1122-1129.

54. Martinez FJ, Foster G, Curtis JL, Criner G, Weinmann G, Fishman A, DeCamp MM, Benditt J, Sciurba F, Make B, et al. Predictors of mortality in patients with emphysema and severe airflow obstruction. Am J Respir Crit Care Med 2006;173:1326-1334.

55. Criner GJ. Effects of long-term oxygen therapy on mortality and morbidity. Respir Care 2000:105-118. 